\title{
The effect of treatment of obstructive sleep apnea syndrome on overactive bladder symptoms
}

\author{
Mutlu Deger ${ }^{1 *}\left(\mathbb{D}\right.$, Ozgur Surmelioglu² (10), Sedat Kuleci ${ }^{3}$ (D), Nebil Akdogan ${ }^{1}$ (D), \\ Muhammed Dagkiran² (D), Ilda Tanrısever ${ }^{2}$ (D), Sevinc Puren Yucel ${ }^{4} \mathbb{B}^{\mathbb{D}}$, Volkan Izol ${ }^{1}$
}

\section{SUMMARY}

OBJECTIVE: To evaluate the effect of the treatment of obstructive sleep apnea syndrome on overactive bladder symptoms. METHODS: All patients who applied to the outpatient clinic with complaints of snoring and apnea were evaluated by polysomnography between years 2017 and 2019. obstructive sleep apnea syndrome severity was evaluated according to the apnea-hypopnea-index. All patients were filled with questionnaire form as overactive bladder symptoms score, international quality of life, international consultation on incontinence questionnaire short-form, and 3-day bladder diary before polysomnography and three months after continuous positive airway pressure therapy and surgical treatment.

RESULTS: A total of 125 patients, 34 (27.2\%) patients with mild obstructive sleep apnea syndrome, 27 (21.6\%) patients with moderate obstructive sleep apnea syndrome, and 64 (51.2) patients with severe obstructive sleep apnea syndrome were included in the study. The prevalence of overactive bladder symptoms in three obstructive sleep apnea syndrome groups were $67.6,53.8$, and $48.4 \%$, respectively, and there was no statistical difference between the groups ( $p=0.190)$. obstructive sleep apnea syndrome treatment such as surgical treatment or continuous positive airway pressure therapy was applied to $45.5 \%$ (31 patients) patients with obstructive sleep apnea syndrome and overactive bladder. Three months after treatment, the overactive bladder symptoms score significantly decreased from 16.1 $\pm 7.9-12.80 \pm 9.82$, international quality of life was significantly increased from 105.0 $\pm 23.2-110.4 \pm 22.2$, and incontinence questionnaire short-form decreased from 11.9 $\pm 4.0-10.4 \pm 5.6(p=0.009, p=0.023$, and $p=0.248$, respectively). There was a significant decrease between before and after treatment in terms of mean day-time frequency and mean urgency episodes of patients ( $p=0.007, p=0.002$ ).

CONCLUSIONS: Both surgery and continuous positive airway pressure treatment of obstructive sleep apnea syndrome improved overactive bladder symptoms, overactive bladder symptoms score, international quality of life, day-time frequency, and urgency episodes.

KEYWORDS: Sleep apnea, obstructive. Urinary bladder, overactive. Continuous positive airway pressure.

\section{INTRODUCTION}

Obstructive sleep apnea syndrome (OSAS) is defined as complete or partial obstruction of the upper respiratory tract during sleep, resulting in airflow reduction or cessation ${ }^{1}$. The standard method for diagnosis of OSAS is polysomnography
(PSG), which measures the apnea-hypopnea index (AHI) ${ }^{2}$. AHI is defined as the sum of apneas and hypopneas per hour of sleep, and OSAS can be classified as mild, moderate, and severe according to $\mathrm{AHI}^{3}$. In the treatment of patients with OSAS, lifestyle changes, oral cavity tools, medical treatment,

\footnotetext{
${ }^{1}$ Çukurova University, Faculty of Medicine, Department of Urology - Adana, Turkey.

${ }^{2}$ Çukurova University, Faculty of Medicine, Department of Otorhinolaryngology - Adana, Turkey.

${ }^{3}$ Çukurova University, Faculty of Medicine, Department of Chest Diseases - Adana, Turkey.

${ }^{4}$ Çukurova University, Faculty of Medicine, Department of Biostatistics - Adana, Turkey.

*Corresponding author: drmutludeger@gmail.com

Conflicts of interest: the authors declare there are no conflicts of interest. Funding: none.

Received on August 06, 2020. Accepted on September 12, 2020.
} 
surgical treatment, and continuous positive airway pressure (CPAP) therapy are used ${ }^{4}$.

Overactive bladder $(\mathrm{OAB})$ prevalence rates range from 49.6 to $79.3 \%$ in patients with OSAS ${ }^{5,6}$. Despite extensive study, the etiopathogenesis of $\mathrm{OAB}$ has not been clearly explained, and the relationship between OSAS and OAB is still under investigation $^{6,7}$. Some studies have explained the relationship between OSAS and OAB by urinary visceral dysfunction caused by hypoxia. However, the effect of severity and treatment of OSAS on the improvement of OAB in patients with OSAS is still unclear and the prevalence studies of OAB in OSAS patients are quite limited ${ }^{5,6,8}$.

In this study, the prevalence of OAB in OSAS severity and the effect of disease treatment on $\mathrm{OAB}$ symptoms were evaluated.

\section{METHODS}

Patients who applied to the outpatient clinic with complaints of snoring and apnea were retrospectively evaluated by PSG after routine otorhinolaryngologic examinations between years 2018 and 2019. Patients diagnosed and treated with benign prostate hyperplasia, interstitial cystitis, neurogenic urinary bladder, urinary tract infection, hematuria, previous urogenital operations, neurological disorders, patients who were taking anticholinergic, $\alpha 1$-blockers and $5 \alpha$-reductase inhibitor, patients who had inadequate and incomplete tests, and patients with $\mathrm{AHI}$ score below 5 were excluded from the study.

PSG tests of patients were performed at the sleep laboratory of Çukurova University, School of Medicine, Department of Chest. The severity of OSAS was determined AHI (mean number of apnea+hypopnea per hour of sleep). In this study, AHI was classified as mild (5-15), moderate (16-30), and severe $(>30)^{9}$. Patients were offered CPAP therapy or surgery according to OSAS severity and patients' clinic.

All patients who applied to the Sleep Disorders Center were filled with a 3-day bladder diary and before PSG was performed and 3 months after CPAP therapy and surgery treatment, all patients were filled with questionnaire form as Overactive Bladder Symptoms Score (OAB-V8), International Consultation on Incontinence Questionnaire Short-Form (ICIQ-SF), and International Quality of Life (I-QOL).

An overactive bladder questionnaire (OAB-q) consists of 33 questions is the first questionnaire form specific to $O A B$ disease and can be used in both wet and dry $O A B$ patients ${ }^{10}$. OAB-V8 consists of the first 8 questions of OAB-q evaluating the daytime frequency, nighttime frequency, urgency, and emergency incontinence and recommended as OAB screening and awareness test ${ }^{11}$. OAB-V8 is preferred for its ease of use in clinical practice. Patients with a total OAB-V8 score $\geq 8$ were considered to be $\mathrm{OAB}$ patients ${ }^{12}$. In our study, $\mathrm{OAB}$ was defined as $\geq 8$ points on the OAB-V8.

I-QOL is a 22 -item questionnaire form into 3 subscales: Avoidance and Limiting Behavior (eight items), Psychosocial Impacts (nine items), and Social Embarrassment (five items). The total I-QOL is calculated by summing the unweighted item score and transforming them to a 100 point scale where $0=$ most severe, and $100=$ no problem.

The ICIQ-SF is formed of six items in the past 4 weeks that evaluate urinary continence. Scores range from 0 to 21 points. Only it was filled by patients with urge incontinence.

In this study, OAB-V8, I-QOL, ICIQ-SF, and nocturia of the patients were compared according to OSAS severity, whose parameters were compared before and 3 months after treatment of OSAS.

\section{Statistical analysis}

All analyses were performed using IBM SPSS Statistics statistical software package, Version 20.0. $\chi^{2}$ test was used to compare categorical variables between the groups. For comparison of continuous variables between two groups, the Mann-Whitney $\mathrm{U}$ test was used. To compare two related continuous variables, Wilcoxon Signed Rank test or the Repeated Measurements Analysis were used, where appropriate. For comparison of more than two groups, Oneway ANOVA or Kruskal Wallis test was used. The statistical level of significance for all tests was considered to be 0.05 .

\section{RESULTS}

A total of 125 patients with the mean age of $49.9 \pm 11.6$ years (range 25-81 years) were included in the study. Of them, 98 (78.4\%) were male and $27(21.6 \%)$ were females $(\mathrm{p}=0.013)$. Patients were classified according to AHI; 34 (27.2\%) patients had mild OSAS, 27 (21.6\%) had moderate, and 64 (51.2\%) had severe OSAS. The mean AHI of mild, moderate, and severe OSAS groups were 8.1 $\pm 2.9,24.0 \pm 9.3$, and 55.8 \pm 19.6 , respectively ( $\mathrm{p}<0.001)$. A comparison of demographic and clinical characteristics between the OSAS groups are presented in Table 1. Gender, age, diabetes mellitus (DM), hypertension (HT), smoking, and alcohol do not differ statistically between the OSAS groups $(\mathrm{p}>0.05)$.

Overactive bladder was observed in 68 patients (54.4\%). Urge urinary incontinence was present in 22 (32.3\%) of patients with $\mathrm{OAB}$. The mean $\mathrm{AHI}$ value of 68 patients with $\mathrm{OAB}$ was 34.9 \pm 27.2 . The prevalence of $\mathrm{OAB}$ in three groups of OSAS were $67.6,53.8$, and $48.4 \%$, respectively $(\mathrm{p}=0.190)$. The mean $\mathrm{OAB}-\mathrm{V} 8$ of patients with $\mathrm{OAB}$ was $16.9 \pm 8.3$ and no significant difference in patients' $\mathrm{OAB}-\mathrm{V} 8$ scores was found between 
Table 1. Baseline characteristics of the study population.

\begin{tabular}{|c|c|c|c|c|}
\hline \multicolumn{5}{|c|}{ OSAS severity } \\
\hline & $\begin{array}{l}\text { Mild } \\
(n=34)\end{array}$ & $\begin{array}{l}\text { Moderate } \\
(n=27)\end{array}$ & $\begin{array}{l}\text { Severe } \\
(n=64)\end{array}$ & $\mathrm{p}$-value \\
\hline AHI value & $\begin{array}{c}8.1 \pm 2.9 \\
7.0(5.0-15.0)\end{array}$ & $\begin{array}{c}24.0 \pm 9.3 \\
22.0(12.0-61.0)\end{array}$ & $\begin{array}{c}55.8 \pm 19.6 \\
52.5(23.0-135.0)\end{array}$ & $<0.001$ \\
\hline Age (years) ${ }^{a}$ & $\begin{array}{c}49.5 \pm 10.7 \\
48.5(31.0-73.0)\end{array}$ & $\begin{array}{c}52.3 \pm 13.0 \\
51.0(29.0-78.0)\end{array}$ & $\begin{array}{c}49.2 \pm 11.5 \\
49.0(25.0-81.0)\end{array}$ & 0.512 \\
\hline \multicolumn{4}{|l|}{ Gender $^{b}$} & \multirow{3}{*}{0.013} \\
\hline Male & $21(61.8)$ & $21(77.8)$ & $56(87.5)$ & \\
\hline Female & $13(38.2)$ & $6(22.2)$ & $8(12.5)$ & \\
\hline $\mathrm{HT}^{\mathrm{b}}$ & $15(44.1)$ & $12(44.4)$ & $28(43.8)$ & 0.998 \\
\hline $\mathrm{DM}^{\mathrm{b}}$ & $10(29.4)$ & $7(25.9)$ & $21(32.8)$ & 0.800 \\
\hline Smoking ${ }^{b}$ & $20(58.8)$ & $19(70.4)$ & $37(57.8)$ & 0.514 \\
\hline Alcoholb $^{\mathrm{b}}$ & $4(11.8)$ & $3(11.1)$ & $9(14.1)$ & 0.908 \\
\hline \multicolumn{4}{|l|}{ Treatment ${ }^{b}$} & \multirow{4}{*}{$<0.001$} \\
\hline Follow up & $23(67.6)$ & $11(40.7)$ & $24(37.5)$ & \\
\hline Surgery & $9(26.5)$ & $8(29.6)$ & $10(15.6)$ & \\
\hline CPAP & $2(5.9)$ & $8(29.6)$ & $30(46.9)$ & \\
\hline
\end{tabular}

OSAS: obstructive sleep apnea syndrome; AHI: apnea-hypopnea index; HT: hypertension; DM: diabetes mellitus; CPAP: continuous positive airway pressure. ${ }^{a}$ Data are expressed as mean \pm standart deviation, median (min-max). bData are expressed as $n$ (\%). Note: bold values indicate statistical significance $(p<0.05)$.

the groups $(\mathrm{p}=0.281)$. The mean I-QOL of these patients was $104.7 \pm 22.1$ and was similar between the groups $(\mathrm{p}=0.539)$. The mean ICIQ-SF of patients with urge incontinence was $11.3 \pm 5.2$ and was similar between the groups $(\mathrm{p}=0.320$ ). The mean voided volume (MVV), mean day-time frequency, mean urgency episodes, and mean frequency of nocturia of patients with $\mathrm{OAB}$ were $262.0 \pm 123.5,8.2 \pm 2.7,4.2 \pm 4.7$, and $2.7 \pm 1.5$, respectively, and there was no significant difference between OSAS groups in terms of these parameters $(\mathrm{p}=0.965$, $\mathrm{p}=0.120, \mathrm{p}=0.210$, and $\mathrm{p}=0.524)$ (Table 2).

Surgical treatment or CPAP therapy was applied to $45.5 \%$ (31 patients) of patients with OAB; (11 patients had surgery, 20 patients with CPAP). There were no significant differences between surgical treatment or CPAP therapy in terms of variables in Table 3 except for the mean voided volume in the $3^{\text {rd }}$ month. The mean voided volume was found to be significantly lower in the surgical treatment group than in the CPAP therapy group $(\mathrm{p}<0.003)$. Hence, due to the insufficient sample size of each treatment group, the patients gathered in one group and comparisons of before and after treatment were applied to this sample $(\mathrm{n}=31)$. Three months after treatment, the OAB-V8 score significantly decreased from 16.1 $\pm 7.9-12.80 \pm 9.82$ ( $\mathrm{p}=0.009$ ). Also, in 9 of 31 patients, the OAB-V8 score decreased below
8, 3 months after treatment. After treatment, the I-QOL significantly increased from 105.0 $\pm 23.2-110.4 \pm 22.2(\mathrm{p}=0.023)$. There was a significant decrease between before and after treatment in terms of mean day-time frequency and mean urgency episodes of patients with $\mathrm{OAB}(\mathrm{p}=0.007, \mathrm{p}=0.002)$. There was no significant difference between before and after treatment in terms of the MVV and mean frequency of nocturia of patients with $\mathrm{OAB}(\mathrm{p}=0.356, \mathrm{p}=0.205)$. In patients with urgent urinary incontinence, ICIQ-SF decreased from 11.9 $\pm 4.0-10.4 \pm 5.6$ after treatment $(\mathrm{p}=0.248)$. Although ICIQ-SF decrease after treatment, the difference was not statistically significant although there was a trend toward significance, which may become significant with larger group sizes (Table 3).

\section{DISCUSSION}

OSAS is causing urologic pathologies, such as erectile dysfunction (ED), nocturia, and $\mathrm{OAB}^{10,13-15}$. Although the pathogenesis of ED and nocturia is clearly demonstrated in patients with OSAS, the mechanism between OAB symptoms and OSAS is still uncertain ${ }^{6,10,13}$. Pathogenesis of OAB is thought to be morphologic changes of the detrusor (e.g., patchy denervation of detrusor muscle bundles), metabolic causes (e.g., disturbed 
Table 2. Comparison of questionnaire form and bladder diary of patients with overactive bladder between obstructive sleep apnea syndrome groups.

\begin{tabular}{|c|c|c|c|c|}
\hline \multicolumn{5}{|c|}{ OSAS severity } \\
\hline & $\begin{array}{l}\text { Mild } \\
\mathrm{n}=23\end{array}$ & $\begin{array}{c}\text { Moderate } \\
n=14\end{array}$ & $\begin{array}{c}\text { Severe } \\
\mathrm{n}=31\end{array}$ & $\mathrm{p}$-value \\
\hline $\mathrm{AHI}$ value ${ }^{\mathrm{a}}$ & $\begin{array}{c}8.5 \pm 2.8 \\
7.0(5.0-15.0)\end{array}$ & $\begin{array}{c}25.0 \pm 11.3 \\
22.0(15.0-61.0)\end{array}$ & $\begin{array}{c}57.3 \pm 23.4 \\
49.0(23.0-135.0)\end{array}$ & $<0.001$ \\
\hline$O A B^{b}$ & $23(67.6)$ & $14(53.8)$ & $31(48.4)$ & 0.190 \\
\hline$O A B-V 8^{a}$ & $\begin{array}{c}18.7 \pm 8.6 \\
17.0(8.0-35.0)\end{array}$ & $\begin{array}{c}17.9 \pm 9.2 \\
16.0(8.0-32.0)\end{array}$ & $\begin{array}{c}15.1 \pm 7.5 \\
12.0(8.0-32.0)\end{array}$ & 0.281 \\
\hline I-QOL ${ }^{\mathrm{a}}$ & $\begin{array}{c}104.1 \pm 23.5 \\
115.0(62.0-132.0)\end{array}$ & $\begin{array}{c}99.6 \pm 24.5 \\
106.0(65.0-126.0)\end{array}$ & $\begin{array}{c}107.5 \pm 20.1 \\
109.0(64.0-132.0)\end{array}$ & 0.539 \\
\hline ICIQ-SFa & $\begin{array}{c}13.7 \pm 5.0 \\
14.0(5.0-21.0)\end{array}$ & $\begin{array}{c}11.2 \pm 3.3 \\
11.0(8.0-15.0)\end{array}$ & $\begin{array}{c}9.7 \pm 5.7 \\
10.0(0.0-20.0)\end{array}$ & 0.320 \\
\hline $\begin{array}{l}\text { Day-time } \\
\text { frequency }^{\text {a }}\end{array}$ & $\begin{array}{c}8.9 \pm 2.5 \\
8.0(6.0-15.0)\end{array}$ & $\begin{array}{c}8.7 \pm 3.7 \\
7.0(5.0-18.0)\end{array}$ & $\begin{array}{c}7.5 \pm 2.2 \\
7.0(4.0-13.0)\end{array}$ & 0.120 \\
\hline Urgency episodes $^{\mathrm{a}}$ & $\begin{array}{c}4.7 \pm 4.2 \\
3.0(0.0-17.0)\end{array}$ & $\begin{array}{c}5.7 \pm 6.7 \\
2.0(0.0-21.0)\end{array}$ & $\begin{array}{c}3.2 \pm 3.7 \\
2.0(0.0-16.0)\end{array}$ & 0.210 \\
\hline $\begin{array}{l}\text { Frequency of } \\
\text { nocturiaa }\end{array}$ & $\begin{array}{c}2.5 \pm 1.3 \\
3.0(0.0-5.0) \\
\end{array}$ & $\begin{array}{c}2.6 \pm 1.8 \\
2.0(1.0-7.0) \\
\end{array}$ & $\begin{array}{c}2.9 \pm 1.4 \\
3.0(0.0-7.0) \\
\end{array}$ & 0.524 \\
\hline $\begin{array}{l}\text { The mean volume } \\
\text { voided }^{\text {a }}\end{array}$ & $\begin{array}{c}256.1 \pm 113.7 \\
214.0(80.0-571.0)\end{array}$ & $\begin{array}{c}259.9 \pm 136.4 \\
268.0(67.0-600.0)\end{array}$ & $\begin{array}{c}267.4 \pm 128.2 \\
250.0(108.0-625.0)\end{array}$ & 0.965 \\
\hline $\begin{array}{l}\text { Total daily urine } \\
\text { volume }(\mathrm{mL})^{\mathrm{a}}\end{array}$ & $\begin{array}{c}2,160.8 \pm 856.9 \\
1,800.0(1,200.0-4,000.0)\end{array}$ & $\begin{array}{c}1,950.0 \pm 646.5 \\
2,000.0(1,000.0-3,000.0)\end{array}$ & $\begin{array}{c}1,890.3 \pm 893.4 \\
1,700.0(1,000.0-5,000.0)\end{array}$ & 0.436 \\
\hline $\begin{array}{l}\text { Total Night-time } \\
\text { urine volume }(\mathrm{mL})^{\mathrm{a}}\end{array}$ & $\begin{array}{c}439.1 \pm 231.0 \\
400.0(0.0-1,000.0)\end{array}$ & $\begin{array}{c}450.0 \pm 250.3 \\
400.0(200.0-1,000.0)\end{array}$ & $\begin{array}{c}570.9 \pm 440.6 \\
500.0(0.0-2,000.0)\end{array}$ & 0.608 \\
\hline
\end{tabular}

OSAS: obstructive sleep apnea syndrome; AHI: apnea-hypopnea index; OAB: overactive bladder; OAB-V8: overactive bladder symptoms scores; I-QOL:

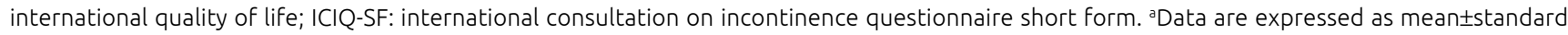
deviation, median (min-max). Note: bold values indicate statistical significance $(p<0.05)$.

Table 3. Comparison of questionnaire form and bladder diary of patients with overactive bladder between before and after obstructive sleep apnea syndrome treatment.

\begin{tabular}{|c|c|c|c|}
\hline & Before treatment & After treatment & $\mathrm{p}$-value \\
\hline OAB-V8a & $\begin{array}{c}16.1 \pm 7.9 \\
13.0(8.0-32.0) \\
\end{array}$ & $\begin{array}{c}12.8 \pm 9.8 \\
9.0(1.0-36.0) \\
\end{array}$ & 0.009 \\
\hline $\mathrm{I}-\mathrm{QOL}^{\mathrm{a}}$ & $\begin{array}{c}105.0 \pm 23.2 \\
109.0(64.0-132.0)\end{array}$ & $\begin{array}{c}110.4 \pm 22.2 \\
120.0(52.0-132.0)\end{array}$ & 0.023 \\
\hline ICIQ-SFa & $\begin{array}{c}11.9 \pm 4.0 \\
12.0(6.0-20.0)\end{array}$ & $\begin{array}{c}10.4 \pm 5.6 \\
11.5(0.0-17.0)\end{array}$ & 0.248 \\
\hline Day-time frequency ${ }^{a}$ & $\begin{array}{c}8.4 \pm 3.0 \\
8.0(4.0-18.0)\end{array}$ & $\begin{array}{c}7.7 \pm 3.3 \\
7.0(4.0-18.0)\end{array}$ & 0.007 \\
\hline Urgency episodes $^{a}$ & $\begin{array}{c}4.3 \pm 5.2 \\
2.0(0.0-21.0)\end{array}$ & $\begin{array}{c}3.4 \pm 5.8 \\
1.0(0.0-22.0)\end{array}$ & 0.002 \\
\hline Frequency of nocturia & $\begin{array}{c}2.6 \pm 1.7 \\
3.0(0.0-7.0)\end{array}$ & $\begin{array}{c}2.4 \pm 2.7 \\
1.0(0.0-10.0)\end{array}$ & 0.205 \\
\hline The mean volume voided $(\mathrm{mL})^{\mathrm{a}}$ & $\begin{array}{c}230.6 \pm 131.2 \\
214.3(66.7-625.0)\end{array}$ & $\begin{array}{c}235.2 \pm 177.0 \\
250.0(75.0-625.0)\end{array}$ & 0.356 \\
\hline Total daily urine volume $(\mathrm{mL})^{\mathrm{a}}$ & $\begin{array}{c}1,748.4 \pm 860.2 \\
1,500.0(1,000.0-5,000.0)\end{array}$ & $\begin{array}{c}1,924.0 \pm 830.8 \\
1,800.0(1,000.0-5,000.0)\end{array}$ & 0.001 \\
\hline Total Night-time urine volume $(\mathrm{mL})^{\mathrm{a}}$ & $\begin{array}{c}567.7 \pm 468.6 \\
500.0(0.0-2,000.0)\end{array}$ & $\begin{array}{c}380.0 \pm 329.5 \\
200.0(0.0-1,200.0)\end{array}$ & 0.013 \\
\hline
\end{tabular}

OAB-V8: overactive bladder symptoms scores; I-QOL: international quality of life; ICIQ-SF: international consultation on incontinence questionnaire

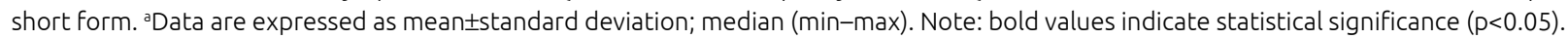


serotonin metabolism), age-related causes of urinary dysfunction, and neurologic changes (e.g., ischemic nerve damage) ${ }^{13}$. Considering these mechanisms that can cause $\mathrm{OAB}$, the relationship between OSAS and OAB is thought to be related to nerve damage caused by hypoxia due to OSAS, as in erectile dysfunction ${ }^{6,13}$. The other possibility is that malfunction of the central nervous system leads to dysregulation of sleep and voiding. The hypothalamus is responsible for the regulation of sleep and arousal, as well as for sending afferent signals directly to the pontine micturition center. Continuous activation of the hypothalamus, which might induce urgency, might fail in its regulation of sleep and arousal ${ }^{16}$. Our study showed that the prevalence of $\mathrm{OAB}$ is quite high in patients with OSAS; however, there is no difference according to prevalence between OSAS severity and it was demonstrated that the treatment of OSAS, regardless of surgery or CPAP therapy, improved OAB symptoms. It was also found that OSAS treatment not only improved the OAB-V8 score but also improved quality of life. In addition, an improvement in day-time frequency and urgency episodes were found.

Ipekci et al. assessed 140 female patients diagnosed with OSAS and reported that OAB symptoms were observed in $79.3 \%$ of patients, but unlike our study, they defined OAB as $\mathrm{OAB}$ symptoms score of $\geq 4$. They found no statistically significant differences between OSAS severity with the prevalence of $\mathrm{OAB}^{6}$. Similarly, Tuncer et al. evaluated the 194 patients diagnosed with OSAS and found no significant difference between OSAS severity in terms of OAB symptoms urgency urinary incontinence ${ }^{5}$. However, Kemmer et al. argued that patients with moderate and severe OSAS had a significantly higher prevalence of $\mathrm{OAB}$ than patients with mild OSAS and control group patients ${ }^{13}$. In this cohort, it had been shown that the prevalence of $\mathrm{OAB}$, urgency urinary incontinence, parameters of bladder diary were similar between OSAS severity.
In the study, Ipekci et al. investigated whether CPAP therapy administered in OSAS patients improves OAB and they concluded that the OAB, OABSS, and ICIQ-SF scores improved in women with severe and moderate OSAS 3 months after treatment $t^{6}$. Similarly, in another study consisted of 73 patients, Dinç et al. concluded that CPAP therapy improved OAB symptoms ${ }^{8}$. The present study evaluated the effect of surgery as well as $\mathrm{CPAP}$ on $\mathrm{OAB}$ symptoms and concluded that both surgery and CPAP improved OAB symptoms, I-QOL, day-time frequency, and urgency episodes.

\section{Limitations of the study}

The limitations of this study are the low number of patients with OSAS and OAB receiving treatment and the small number of women included in the study. Another limitation is that urodynamic studies were not used for the diagnosis of $O A B$, only questionnaire forms and bladder diary were made.

\section{CONCLUSIONS}

The prevalence of OAB was higher in OSAS patient; however, there was no difference in the prevalence of $\mathrm{OAB}$ between OSAS severity. Both surgery and CPAP therapy of OSAS improved OAB symptoms, I-QOL, day-time frequency, and urgency episodes.

\section{AUTHORS' CONTRIBUTION}

MD: Conceptualization, Data curation, Formal analysis, Investigation, Methodology, Validation, Writing - original draft. OS: Data curation, Investigation, Methodology, Project administration, Supervision. SK: Data curation, Writing - review \& editing. IT: Data curation. NA: Formal analysis, Visualization. SPY: Formal analysis. VI: Project administration, Supervision, Writing - review \& editing. MD: Validation, Visualization.

\section{REFERENCES}

1 Parati G, Lombardi C, Narkiewicz K. Sleep apnea: epidemiology, pathophysiology, and relation to cardiovascular risk. Am J Physiol Regul Integr Comp Physiol. 2007;293(4):R1671-83. https://doi.org/10.1152/ajpregu.00400.2007

2 Kapur VK, Auckley DH, Chowdhuri S, Kuhlmann DC, Mehra $\mathrm{R}$, Ramar K, et al. Clinical practice guideline for diagnostic testing for adult obstructive sleep apnea: an american academy of sleep medicine clinical practice guideline. J Clin Sleep Med. 2017;13(3):479-504. https://doi.org/10.5664/ jcsm.6506

3 Vaughn BV, Giallanza P. Technical review of polysomnography. Chest. 2008;134(6):1310-9. https://doi.org/10.1378/ chest.08-0812
4 Semelka M, Wilson J, Floyd R. Diagnosis and treatment of obstructive sleep apnea in adults. Am Fam Physician. 2016;94(5):355-60. PMID: 27583421

5 Tuncer M, Yazici O, Kafkasli A, Sabuncu K, Salepci B, Narter F, et al. Critical evaluation of the overactive bladder and urgency urinary incontinence association with obstructive sleep apnea syndrome in a relatively young adult male population. Neurourol Urodyn. 2017;36(7):1804-8. https://doi.org/10.1002/nau.23184

6 Ipekci T, Cetintas G, Celik O, Ekin RG, Sarac S, Tunckiran A, et al. Continuous positive airway pressure therapy is associated with improvement in overactive bladder symptoms in women with obstructive sleep apnea syndrome. Cent European J Urol. 2016;69(1):78-82. https://doi.org/10.5173/ceju.2016.674 
7 Leron E, Weintraub AY, Mastrolia SA, Schwarzman P. Overactive bladder syndrome: evaluation and management. Curr Urol. 2018;11(3):117-25. https://doi. org/10.1159/000447205

8 Dinç ME, Avinçsal MÖ, Balcı MBC, Özdemir C. Effect of continuous positive airway pressure on overactive bladder symptoms in patients with obstructive sleep apnea syndrome. Turk Arch Otorhinolaryngol. 2018;56(3):133-8. https://doi. org/10.5152/tao.2018.3251

9 American Academy of Sleep Medicine. International classification of sleep disorders, revised: diagnostic and coding manual. Chicago: American Academy of Sleep Medicine; 2001. p.51-5.

10 Pascual M, Batlle J, Barbé F, Castro-Grattoni AL, Auguet JM, Pascual $\mathrm{L}$, et al. Erectile dysfunction in obstructive sleep apnea patients: a randomized trial on the effects of Continuous Positive Airway Pressure (CPAP). PLoS One. 2018;13(8):e0201930. https://doi.org/10.1371/journal.pone.0201930

11 Acquadro C, Kopp Z, Coyne KS, Corcos J, Tubaro A, Choo $M S$, et al. Translating overactive bladder questionnaires in 14 languages. Urology. 2006;67(3):536-40. https://doi. org/10.1016/j.urology.2005.09.035
12 Coyne KS, Zyczynski T, Margolis MK, Elinoff V, Roberts RG. Validation of an overactive bladder awareness tool for use in primary care settings. Adv Ther. 2005;22(4):381-94. https:// doi.org/10.1007/BF02850085

13 Kemmer H, Mathes AM, Dilk O, Gröschel A, Grass C, Stöckle M. Obstructive sleep apnea syndrome is associated with overactive bladder and urgency incontinence in men. Sleep. 2009;32(2):271-5. https://doi.org/10.1093/sleep/32.2.271

14 Miyauchi Y, Okazoe H, Okujyo M, Inada F, Kakehi T, Kikuchi H, et al. Effect of the continuous positive airway pressure on the nocturnal urine volume or night-time frequency in patients with obstructive sleep apnea syndrome. Urology. 2015;85(2):333-6. https://doi.org/10.1016/j.urology.2014.11.002

15 Miyazato M, Tohyama K, Touyama M, Nakamura H, Oshiro T, Ueda S, et al. Effect of continuous positive airway pressure on nocturnal urine production in patients with obstructive sleep apnea syndrome. Neurourol Urodyn. 2017;36(2):376-9. https://doi.org/10.1002/nau.22936

16 Tsujimura A, Takao T, Miyagawa Y, Yamamoto K, Fukuhara S, Nakayama J, et al. Urgency is an independent factor for sleep disturbance in men with obstructive sleep apnea. Urology. 2010;76(4):967-70. https://doi.org/10.1016/j.urology.2010.01.070 